\title{
PHƯƠNG PHÁP MỚI TRONG VIÊC NÂNG CAO QUÁ TRÌNH THIẾT KẾ CẤP PHỐI BÊ TỔNG CƯỜnG ĐỘ CAO
}

\author{
NGUYẼ̃N VIỆT ĐỨC ${ }^{(1)}$, PHÙNG VĂN BİNH ${ }^{(2)}$, ĐẶNG HOÀNG MINH ${ }^{(3)}$ \\ ${ }^{(1)}$ Khoa Kỹ thuật Xây dưng, Trường Đại học Công nghiệp thành phố Hồ Chí Minh, \\ (2) Trường Đại học Tổng hợp Quốc gia Matxcova mang tên N.E. Bauman, Liên Bang Nga, \\ ${ }^{(3)}$ Khoa Công nghệ Co khí, Trường Đại hoc Công nghiệp thành phố Hồ Chí Minh; \\ nguyenvietduc@iuh.edu.vn,phungvanbinh.vp@gmail.com, hoangminh_ru@mail.ru
}

Tóm tắt. Bê tông cường độ cao - chất lượng cao ngày càng được sử dụng rộng rãi ở Việt Nam trong thi công các công trình quan trọng như cầu, hầm đường bộ. Bài báo này đề xuất một phương pháp mới trong việc nâng cao quá trình thiết kế cấp phối cho bê tông loại này, đó là sử dụng phương pháp "Visual Interactive Analysis Method (VIAM)" cùng với kỹ thuật khảo sát không gian tham biến. Một mô hình toán học tổng thể được thiết lập với mục đích tối ưu hóa sáu tiêu chuẩn, đó là hệ số thẩm thấu của ion clorua của bê tông, giá thành của một mét khối bê tông, thành phần của xi măng, tro bay, xỉ lò cao mịn và phụ gia hóa học trong một mét khối bê tông. Mô hình toán học này cần phải thỏa mãn mười điều kiện ràng buộc phiếm hàm và các ràng buộc của bảy tham biến thiết kế. Cuối cùng, mười hai lời giải Pareto đã được tìm cho tình huống chỉ định bởi các chuyên gia về các tiêu chuẩn trong quá trình tìm kiếm phương án thiết kế cấp phối bê tông cường độ cao - chất lượng cao.

Từ khóa. Bê tông cường độ cao-chất lượng cao, thiết kế cấp phối, tối ưu hóa đa mục tiêu, lời giải Pareto, VIAM - phương pháp tương tác và phân tích trực quan

\section{A NEW METHOD FOR IMPROVING HIGH PERFORMANCE CONCRETE MIX PROPORTION}

\begin{abstract}
High Performance Concrete has been used more and more broadly for engineering transportation structures in Vietnam such as bridges, tunnels, highways. This paper proposes a new method for improving high performance concrete mix proportion, which involves with the use of Visual Interactive Analysis Method (VIAM) together with a technique of spatial parameter survey. An integrated mathematical model was developed in order to optimize six criteria, which are the chlorine ion diffusion coefficient, per cubic meter cost, the amount of cement, fly ash, slag, chemical admixture. This model needs to satisfy with ten functional constraints and seven design variables. Finaly, twelve Pareto solutions have been found for the particular case determined by the experts in terms of criteria during the process of proportioning high - performance concrete mix.
\end{abstract}

Keywords. High performance concrete, mix proportion, multi-objective optimization, Pareto solution, VIAM - Visual and Interactive Analysis Method

\section{GIỚI THIỆU CHUNG}

Ngày nay trên thế giới các công trình xây dựng sử dụng bê tông diễn ra với quy mô ngày càng lớn. Do các xu hướng gần đây trong ngành xây dựng, như sự gia tăng số lượng lớn của kết cấu bê tông cốt thép, xây dựng với các loại kết cấu với kích thước lớn hơn, và sự phát triển của các kỹ thuật xây dựng mới, cho nên nhu cầu đòi hỏi phải sản xuất một khối lượng bê tông rất lớn. Điều này đã đặt ra yêu cầu cấp thiết cho độ bền và an toàn của bê tông. Để đảm bảo vấn đề này, nhiều nghiên cứu đã được tập trung vào việc phát triển bê tông cường độ cao và chất lượng cao. Loại bê tông này được thiết kế nhằm mục đích sau: tối ưu hóa các tính năng đặc trưng cho một loại vật liệu xây dựng, tăng tính năng sử dụng và điều kiện tiếp xúc, 
tăng độ cứng, tăng tính công tác, tăng độ bền và tuổi thọ làm việc. Do đó, bê tông loại này rất cần thiết cho các hạng mục kết cấu trong điều kiện môi trường khắc nghiệt như các công trình biển, cầu đường, vỉa hè, các kết cấu cho công trình hạt nhân, đường hầm $[1,5-7]$.

Bên cạnh đó ở Việt Nam trong những năm gần đây, bê tông cường độ cao và chất lượng cao đã đóng một vai trò quan trọng trong các công trình xây dựng như cầu, đường, các tòa nhà cao tầng tại các thành phố lớn (Hà Nội, TP. Hồ Chí Minh, Đà Nẵng). Tiêu biểu là trong xây dựng các công trình cầu bê tông cốt thép và đường hầm bằng các công nghệ mới, thì bê tông cường độ cao và chất lượng cao đã được sử dụng tương đối hiệu quả, chẳng hạn như nút giao thông tại Cầu Dương Chương tại Hà Nội, đường hầm Hải Vân ở Đà Nẵng hay đường hầm Thủ Thiêm tại TP. Hồ Chí Minh [6,7].

Sự khác biệt rõ nét giữa bê tông chất lượng cao với bê tông thường là việc sử dụng các phụ gia hóa chất (các chất làm thay đổi thành phần hóa học của bê tông) và phụ gia khoáng (nguyên liệu có chứa nhiều khoáng chất để làm tăng độ đặc chắc của bê tông, chứ không làm thay đổi thành phần hóa học). Phụ gia hóa học có thể làm giảm hàm lượng nước và đồng thời làm giảm độ xốp trong hồ xi măng ngậm nước, tuy nhiên việc lạm dụng phụ gia hóa học với hàm lượng cao để giảm hàm lượng nước tới một giá trị rất thấp là điều không nên áp dụng vì còn phụ thuộc vào nhiều yếu tố như là nhiệt độ của môi trường xung quanh, thành phần hóa học và độ mịn của xi măng. Trong khi đó, phụ gia khoáng, hay còn được gọi là vật liệu thay thế xi măng, đóng vai trò như pozzolanic; do đó, các vi kết cấu của ma trận xi măng sẽ trở nên đặc chắc hơn. Ở nhiệt độ thường của môi trường xung quanh, phản ứng hóa học với canxi hydroxit nói chung là chậm. Tuy nhiên, các tinh thể pozzolan càng mịn, thì các phản ứng này sẽ diễn ra nhanh hơn. Nếu tuổi thọ là mối quan tâm chính, thì độ ninh kết và đông kết chậm do sự tham gia của tro bay hoặc tro xỉ trong bê tông là yếu tố thuận lợi. Ngoài ra, các phụ gia khoáng nói chung là các sản phẩm phụ của một số ngành công nghiệp, cho nên việc sử dụng chúng có thể đem lại lợi ích kinh tế lớn [4,5,7].

Do đó, việc sử dụng kết hợp các phụ gia siêu dẻo và phụ gia khoáng có thể mang lại hiệu quả kinh tế kỹ thuật cho bê tông cường độ cao và chất lượng cao như là tăng độ cứng tăng tính công tác và tăng tuổi thọ. Thêm nữa, việc sử dụng phụ gia khoáng đã được báo cáo là sẽ dẫn đến độ thấm thấp hơn, giảm nhiệt hydrat hóa, làm giảm phản ứng kiềm-tổng hợp, tăng độ bền lâu, và tăng sức kháng dưới tác dụng của gốc sunfat. Tuy nhiên, tác dụng của phụ gia khoáng lên bê tông thay đổi rõ rệt phụ thuộc vào tính chất của từng loại [4]. Để có được sự kết hợp hiệu quả và thống nhất, thì việc tính toán tối ưu hóa cấp phối cho bê tông cường độ cao và chất lượng cao là điều rất cần thiết.

Tiếp nối theo nghiên cứu khả quan gần đây của nhóm tác giả [6], bài báo này đưa ra một phương pháp mới trong việc nâng cao quá trình thiết kế cấp phối cho bê tông cường độ cao và chất lượng cao với các thành phần vật liệu là xi măng Portland, nước, tro bay, tro xỉ mịn, cát, đá và phụ gia hóa học. Ý tưởng của phương pháp này là giải quyết bài toán tối ưu đa mục tiêu hàm nhiều chuẩn, với mục đích chính là nhằm đưa ra giải pháp tối ưu nhất cho loại bê tông này như: bê tông có hàm lượng các vật liệu đắt tiền như là xi măng, tro xỉ mịn, tro bay và phụ gia hóa học được tối ưu nhất, đồng thời độ thẩm thấu (là tính năng thể hiện độ bền của bê tông) và giá thành của $1 \mathrm{~m}^{3}$ bê tông cũng được tối ưu nhất.

\section{PHÁT BIỂU YÊU CẦU CỦA BÀI TOÁN}

Trong công trình của Xie và cộng sự [9], một mô hình toán thiết kế đa mục tiêu cấp phối bê tông cường độ cao đã được xây dựng. Tuy nhiên các tác giả chỉ dừng lại ở việc xét đến 2 tiêu chuẩn là hệ số thẩm thấu của ion clorua và giá thành của $1 \mathrm{~m}^{3}$ bê tông. Trên thực tế, khối lượng của các thành phần với giá thành cao như xi măng Portland, tro bay, tro xỉ mịn và phụ gia hóa học cũng là những tiêu chuẩn rất cần thiết được xem xét để giảm thiểu một cách tối đa khi thiết kế. Chính vì vậy, trong bài báo này, một mô hình thiết kế đa mục tiêu cấp phối bê tông cường độ cao tổng quát đã được xây dựng để thích ứng hơn với quá trình sản xuất trong điều kiện thực tế ở Việt Nam.

Mô hình toán học của bài toán nghiên cứu được thể hiện trong sơ đồ Hình 1 bên dưới [6]. 


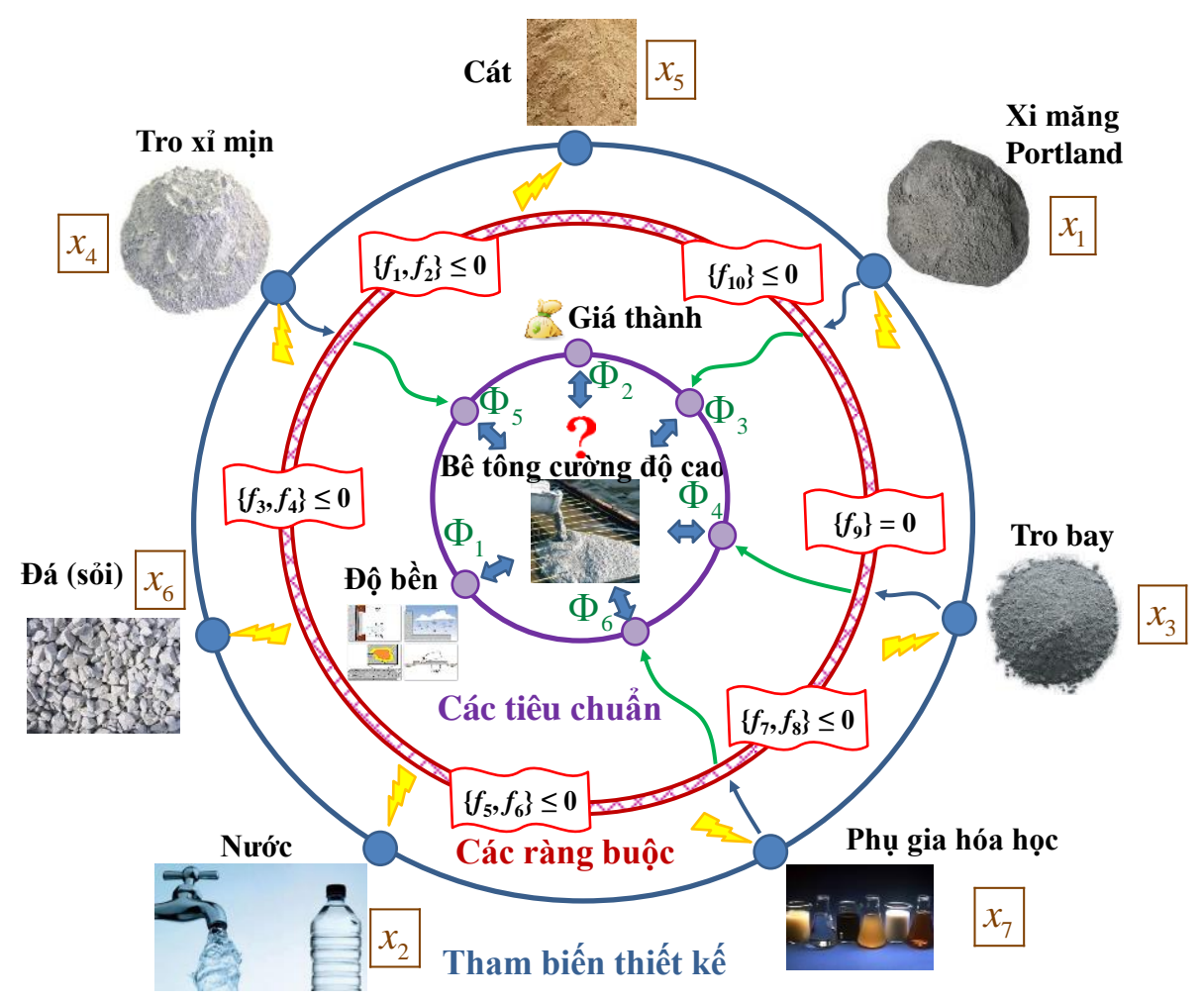

Hình 1: Mô hình thiết kế cấp phối đa mục tiêu cho bê tông cường độ - chất lượng cao

Mô hình toán được bắt đầu với 7 tham biến thiết kế (từ $x_{1}$ đến $x_{7}$ ) được phân bố xung quanh vòng tròn ngoài cùng của hình 1 . Chúng cũng là 7 tham biến mà chúng ta sẽ sử dụng để điều khiển sau này trong quá trình thiết kế đa mục tiêu cấp phối bê tông cường độ cao - chất lượng cao. Ký hiệu, ý nghĩa, đơn vị và miền xác định của 7 tham biến này được miêu tả cụ thể trong bảng 1 . Với mỗi một véc tơ giá trị xác định $\{\mathbf{x}\}=\left(x_{1}, x_{2}, \ldots, x_{7}\right)$ của 7 tham biến này, ta lần lượt tính giá trị của 10 hàm số cho véc tơ ràng buộc phiếm hàm $\{\mathbf{f}\}=\left(f_{1}, x_{2}, \ldots, f_{10}\right)$. Ký hiệu, biểu thức tính, điều kiện cụ thể và ý nghĩa của các ràng buộc này được miêu tả trong bảng 2 . Theo đó, thì 10 điều kiện này giống như một "bộ lọc" (vòng tròn màu đỏ có đan lưới chữ thập trong hình 1$)$. Chỉ cần một ràng buộc $f_{i}(\mathbf{x}), i=1 . .10$ không được thỏa mãn thì véc tơ tham biến $\{\mathbf{x}\}$ được coi là không hợp lệ, và cần tìm các véc tơ $\{\mathbf{x}\}$ hợp lệ khác trong quá trình tìm kiếm lời giải. Véc tơ nào "lọt qua" 10 điều kiện trên sẽ được tiếp tục tính giá trị cho 6 tiêu chuẩn chất lượng $\{\boldsymbol{\Phi}\}=\left(\Phi_{1}, \Phi_{2}, \ldots, \Phi_{6}\right)$ của bê tông cường độ cao mà các chuyên gia cần thiết kế cấp phối. Chúng được sắp xếp bao quanh vòng tròn màu tím trong cùng trong hình 1 . Ký hiệu, xu hướng tối ưu hóa (MIN hoặc MAX), biểu thức xác định và ý nghĩa của từng tiêu chuẩn được chú giải trong bảng số 3 . Như vậy thì trung tâm của quá trình thiết kế này là $1 \mathrm{~m}^{3}$ bê tông cường độ cao, chất lượng cao, được đặt tại tâm của các vòng tròn trong sơ đồ hình 1 . Tất cả 3 vòng tròn tham biến điều khiển - ràng buộc phiếm hàm - tiêu chuẩn chất lượng này hợp lại thành mô hình thiết kế cấp phối bê tông mà chúng ta cần giải quyết.

\section{a. Các tham biến thiết kế:}

Các tham biến điều khiển và ràng buộc của chúng trong mô hình bài toán được liệt kê ở Bảng $1[6,9]$ : 
CÂP PHỐI BÊ TỐNG CUOÒ̀NG ĐỘ CAO

Bảng 1: Các tham biến điều khiển thiết kế và ràng buộc của chúng

\begin{tabular}{|c|c|c|c|c|}
\hline Tham biến & Ý nghĩa: Số lượng vật liệu & Đơn vị & $\begin{array}{c}\text { Giá trị thấp nhất } \\
\text { đurợc chấp nhận }\end{array}$ & $\begin{array}{c}\text { Giá trị lớn nhất đuợc } \\
\text { chấp nhận }\end{array}$ \\
\hline$x_{1}$ & Xi măng Portland & $\mathrm{kg} / \mathrm{m}^{3}$ & 300 & 500 \\
\hline$x_{2}$ & Nước & $\mathrm{kg} / \mathrm{m}^{3}$ & 130 & 210 \\
\hline$x_{3}$ & Tro bay & $\mathrm{kg} / \mathrm{m}^{3}$ & 45 & 155 \\
\hline$x_{4}$ & Tro xỉ mịn & $\mathrm{kg} / \mathrm{m}^{3}$ & 60 & 200 \\
\hline$x_{5}$ & Cát & $\mathrm{kg} / \mathrm{m}^{3}$ & 500 & 1000 \\
\hline$x_{6}$ & Đá (sỏi) & $\mathrm{kg} / \mathrm{m}^{3}$ & 900 & 1400 \\
\hline$x_{7}$ & Phụ gia hóa học & $\mathrm{kg} / \mathrm{m}^{3}$ & 2.5 & 12 \\
\hline
\end{tabular}

\section{b. Ràng buộc phiếm hàm}

Các ràng buộc phiếm hàm được trình bày theo các hệ thức và phương trình trong Bảng 2 [6,9]:

Bảng 2: Các ràng buộc phiếm hàm

\begin{tabular}{|c|c|c|c|}
\hline $\begin{array}{l}\text { Phiếm } \\
\text { hàm }\end{array}$ & Biểu thức & $\begin{array}{c}\text { Dạng ràng } \\
\text { buộc }\end{array}$ & Ýnghĩa \\
\hline$f_{1}$ & $-\frac{x_{2}}{x_{1}+x_{3}+x_{4}}+0.2$ & $\leq 0$ & \multirow{2}{*}{$\begin{array}{l}\text { Biên độ của tỷ lệ nước so với bộ } \\
\text { mịn. }\end{array}$} \\
\hline$f_{2}$ & $\frac{x_{2}}{x_{1}+x_{3}+x_{4}}-0.4$ & $\leq 0$ & \\
\hline$f_{3}$ & $-\frac{x_{5}}{x_{5}+x_{6}}+0.35$ & $\leq 0$ & \multirow{2}{*}{$\begin{array}{l}\text { Biên độ của tỷ lệ cát, tức là tỷ lệ } \\
\text { của hàm lượng cát so với hàm } \\
\text { lượng tống của cốt liệu sử dụng } \\
\text { (cát+đá) }\end{array}$} \\
\hline$f_{4}$ & $\frac{x_{5}}{x_{5}+x_{6}}-0.4$ & $\leq 0$ & \\
\hline$f_{5}$ & $450-\left(x_{1}+x_{3}+x_{4}\right)$ & $\leq 0$ & \multirow{2}{*}{$\begin{array}{l}\text { Biên độ của hàm lượng chất kết } \\
\text { dính bao gồm xi măng, tro bay và } \\
\text { xỉ lò cao. }\end{array}$} \\
\hline$f_{6}$ & $x_{1}+x_{3}+x_{4}-600$ & $\leq 0$ & \\
\hline$f_{7}$ & $-\frac{x_{7}}{x_{1}+x_{3}+x_{4}}+0.01$ & $\leq 0$ & \multirow{2}{*}{$\begin{array}{l}\text { Phụ gia hóa học giảm nước biên } \\
\text { độ cao được sự dụng để tăng } \\
\text { cường tính công tác của bê tông } \\
\text { tươi và vi cấu trúc của bê tông. } \\
\text { Đó là tỷ lệ của phụ gia hóa học so } \\
\text { với hàm lượng xi măng sử dụng. }\end{array}$} \\
\hline$f_{8}$ & $\frac{x_{7}}{x_{1}+x_{3}+x_{4}}-0.02$ & $\leq 0$ & \\
\hline$f_{9}$ & $\sum_{i=1}^{7} \frac{x_{i}}{\rho_{i}}-990$ & $=0$ & $\begin{array}{l}\text { Thể tích của hỗn hợp bề tông } \\
\text { được cấu thành từ thề tích tuyệt } \\
\text { đối của các thành phần và thể tích } \\
\text { của không khí cuốn vào trong } \\
\text { hỗn hợp. Biểu thức này cần phải } \\
\text { được thỏa mãn đối với tất cả các } \\
\text { loại vật liệu được sử dụng trong } \\
1 \mathrm{~m}^{3} \text { hồn hợp bê tông. }\end{array}$ \\
\hline$f_{10}$ & $\begin{array}{l}-0.304 \lambda_{c} f_{c e, k}\left(\frac{x_{1}+x_{3}+x_{4}}{x_{2}}+0.62\right) \\
+f_{c u, k}-t \sigma\end{array}$ & $\leq 0$ & $\begin{array}{l}\text { Cường độ nén của bê tông, mà bị } \\
\text { ảnh hương bởi rất nhiều các yếu } \\
\text { tố khác nhau, là một chỉ số quan } \\
\text { trọng trong tính toán thiết kế cấp } \\
\text { phối bê tông. }\end{array}$ \\
\hline
\end{tabular}


Trong đó, $\rho_{\mathrm{i}}(i=1 . .7)$ là khối lượng riêng của mỗi thành phần vật liệu của bê tông (tấn/m3): $\rho_{1}=3.11$; $\rho_{2}=1 ; \rho_{3}=2.11 ; \rho_{4}=2.45 ; \rho_{5}=2.61 ; \rho_{6}=2.76 ; \rho_{7}=1.08$. $\lambda_{\mathrm{c}}$ là hệ số ảnh hưởng đến mác của bê tông, được xác định dựa trên thống kê, và trong các trường hợp nói chung có giá trị là $1.13 ; f_{\mathrm{ce}, \mathrm{k}}$ là giá trị thể hiện mác của bê tông, trong nghiên cứu này mác bê tông chất lượng cao-cường độ cao mác 600 được chọn hay $f_{\mathrm{ce}, \mathrm{k}}=60 ; \mathrm{f}_{\mathrm{cu}, \mathrm{k}}$ thể hiện cường độ tiêu chuẩn của bê tông khi đo bằng khối lập phương và $f_{\mathrm{cu}, \mathrm{k}}=$ 68 ; $\mathrm{t}$ là hệ số xác suất và $t=-1.64 ; \sigma$ là độ lệch tiêu chuẩn của cường độ của bê tông, và được xác định dựa theo tiêu chuẩn GB50204 đối với chất lượng xây dựng của công trình sử dụng bê tông và $\sigma=5$.

\section{c. Các hàm tiêu chuẩn chất lượng}

Các hàm tiêu chuẩn chất lượng được thể hiện trong Bảng 3 bên dưới $[6,9]$ :

Bảng 3: Các hàm tiêu chuẩn chất lượng

\begin{tabular}{|c|c|c|}
\hline Tiêu chuẩn & Biểu thúc & Ý nghĩa \\
\hline $\boldsymbol{\Phi}_{1} \rightarrow \mathrm{MIN}$ & $\begin{array}{l}\left\{\left[5.760+5.81 \cdot\left(\frac{x_{2}}{x_{1}+x_{3}+x_{4}}-0.45\right) / 0.2\right.\right. \\
-0.567 \cdot\left(x_{1}+x_{3}+x_{4}-425\right) / 175+1.323 \\
+0.74 \cdot\left(\frac{x_{3}}{x_{1}+x_{3}+x_{4}} \cdot 100-22.5\right) / 22.5 \\
-2.117 \cdot\left(\frac{x_{4}}{x_{1}+x_{3}+x_{4}} \cdot 100-35\right) / 35 \\
-(2.78 \cdot 0.472)-(0.254 \cdot 0.286)-(0.368 \cdot 1) \\
+1.171 \cdot \frac{\frac{x_{1}+x_{3}+x_{4}}{0.2}-0.45}{0.2} \cdot \frac{x_{3}+x_{3}+x_{4}}{22.5} \cdot 100-22.5 \\
-2.891 \cdot \frac{\frac{x_{2}}{x_{1}+x_{3}+x_{4}}-0.45}{0.2} \cdot 0.472 \\
-1.053 \cdot \frac{\frac{x_{3}}{x_{1}+x_{3}+x_{4}} \cdot 100-22.5}{22.5} \cdot 10^{-6} \\
\left.\frac{365 \cdot 24 \cdot 3600}{2}\right]^{2}\end{array}$ & $\begin{array}{l}\text { Hệ số thẩm thấu của ion } \\
\text { clorua ở ngày thứ } 28 \text { đối } \\
\text { với bê tông không sử dụng } \\
\text { xỉ mịn silica với khuôn đúc } \\
\text { ở nhiệu độ } 21^{\circ} \mathrm{C}\left(\mathrm{m}^{2} / \mathrm{s}\right)\end{array}$ \\
\hline $\boldsymbol{\Phi}_{2} \rightarrow \mathrm{MIN}$ & $\sum_{i=1}^{7}\left(y_{i} \cdot x_{i}\right)$ & $\begin{array}{l}\text { Giá thành của } 1 \mathrm{~m}^{3} \text { bê tông } \\
\left(\mathrm{VND} / \mathrm{m}^{3}\right)\end{array}$ \\
\hline $\boldsymbol{\Phi}_{3} \rightarrow \mathrm{MIN}$ & $x_{1}$ & $\begin{array}{l}\text { Hàm lượng xi măng } \\
\text { Portland trong } 1 \mathrm{~m}^{3} \text { bê tông } \\
\left(\mathrm{kg} / \mathrm{m}^{3}\right)\end{array}$ \\
\hline $\boldsymbol{\Phi}_{4} \rightarrow \mathrm{MIN}$ & $x_{3}$ & $\begin{array}{l}\text { Hàm lượng tro bay trong } \\
1 \mathrm{~m}^{3} \text { bê tông }\left(\mathrm{kg} / \mathrm{m}^{3}\right)\end{array}$ \\
\hline $\boldsymbol{\Phi}_{5} \rightarrow \mathrm{MIN}$ & $x_{4}$ & $\begin{array}{l}\text { Hàm lượng xî lò cao trong } \\
1 \mathrm{~m}^{3} \text { bê tông }\left(\mathrm{kg} / \mathrm{m}^{3}\right)\end{array}$ \\
\hline $\boldsymbol{\Phi}_{6} \rightarrow \mathrm{MIN}$ & $x_{7}$ & $\begin{array}{l}\text { Hàm lượng phụ gia hóa } \\
\text { học trong } 1 \mathrm{~m}^{3} \text { bê tông } \\
\left(\mathrm{kg} / \mathrm{m}^{3}\right)\end{array}$ \\
\hline
\end{tabular}


Trong đó, $y_{i}(i=1 . .7)$ là đơn giá của mỗi thành phần vật liệu của bê tông (VND/kg): $y_{1}=1500 ; y_{2}=$ $12 ; y_{3}=550 ; y_{4}=5050 ; y_{5}=118 ; y_{6}=135 ; y_{7}=21000$.

Theo mô hình toán này, chúng ta cần tối ưu 6 tiêu chuẩn chất lượng $\boldsymbol{\Phi}_{i}(i=1 . .6)$ trong khuôn khổ phải thỏa mãn 10 điều kiện ràng buộc phiếm hàm $f_{j}(j=1 . .10)$ và các ràng buộc của 7 tham biến thiết kế $x_{k}(k$ $=1 . .7$ ).

\section{PHƯƠNG PHÁP TƯƠNG TÁC VÀ PHÂN TÍCH TRƯC QUAN (VIAM) TRONG THIẾT KẾ ĐA MỤC TIÊU CẤP PHỐI BÊ TÔNG VÄ KÊTT QUẢ TÍNH TOÁN}

Trong những năm gần đây, các phương pháp tối ưu hóa một và nhiều tiêu chuẩn được nghiên cứu khá phổ biến. Tuy nhiên, hầu như các nghiên cứu này đều tập trung vào việc phát triển các thuật toán tối ưu cho hàm một tiêu chuẩn. Việc xử lý bài toán nhiều mục tiêu phần lớn được thực hiện bằng nhiều cách chuyển đổi về một tiêu chuẩn chung - đại diện, ví dụ như phương pháp Weighted Minimax (Maximin), Compromise Programming, Weighted Sum, Bounded Objective Function, Modified Tchebycheff, Weighted Product, Exponential Weighted Sum, v.v...

Công trình của Xie và cộng sự [9] cũng lựa chọn phương pháp giải quyết như vậy. Sau khi đưa về một tiêu chuẩn tương đương, các tác giả này đã sử dụng phương pháp Sequencial Quadratic Programming để tìm cực trị của nó. Cần nhấn mạnh rằng, có thể sử dụng nhiều giải thuật khác nhau như giải thuật Cooko, đom đóm, lai ghép, di truyền, bầy đàn, v.v... để tìm cực trị của hàm tương đương này. Mỗi một giải thuật nói trên đưa ra những giá trị tối ưu với độ chệnh lệch không nhiều. Tuy nhiên, điều đáng bàn luận là ở chỗ, với giá trị cực tiểu của hàm tương đương tìm được, thì giá trị của từng tiêu chuẩn riêng biệt lại khác nhau. Có nghĩa là, có những tiêu chuẩn với một giải thuật này thì tối ưu hơn, nhưng tiêu chuẩn khác thì lại không bằng ở một giải thuật khác.

Có hai câu hỏi chưa được xem xét một cách chi tiết trong các công trình kể trên khi áp dụng chiến lược tối ưu một tiêu chuẩn:

- Liệu tiêu chuẩn tương đương có thể thực sự thay thế cho việc xét từng tiêu chuẩn riêng biệt hay không, khi mà mức độ quan trọng của từng tiêu chuẩn dưới góc nhìn của mỗi một chuyên gia, ở một thời điểm cụ thể, trong một bối cảnh sản xuất cụ thể khác nhau là khác nhau?

- Trong quá trình gia công, sản xuất thực tế, các chuyên gia làm thế nào để có thể phân tích trực tiếp, cân nhắc mức độ ưu tiên cho các tiêu chuẩn một cách linh động, để từ đó có những quyết toán phù hợp?

Ý nghĩa của các giải thuật tối ưu là vô cùng to lớn, nhưng trong điều kiện thực tế, khi cần sự linh động thỏa hiệp để tìm phương án sản xuất hợp lệ, các tiêu chuẩn cần phải được cân nhắc một cách riêng biệt, lặp lại nhiều lần trong quá trình so sánh, tiếp theo là các quá trình "nhượng bộ" để đạt được sự đồng thuận với các tiêu chuẩn khác. Điều này đòi hỏi cần có một công cụ, một phương pháp xử lý bài toán đa mục tiêu mang tính chất ứng dụng cao. Bài báo này đề xuất một trong số những phương pháp đó - the Visual Interactive Analysis Method (VIAM): Kỹ thuật khảo sát không gian tham biến và áp dụng nó để giải quyết bài toán thiết kế đa mục tiêu cấp phối bê tông cường độ - chất lượng cao.

Mô tả của phương pháp VIAM được trình bày chi tiết trong công trình của Gavriushin và Dang [3]. Ý tưởng chính của phương pháp này nằm ở chỗ: Đầu tiên cần thiết lập bảng tương tác, chứa miền giá trị của các tiêu chuẩn sau khi đã thỏa mãn tất cả ràng buộc. Các chuyên gia dựa vào bối cảnh và nhu cầu sản xuất cụ thể, đưa ra các yêu cầu về ngưỡng giá trị của các tiêu chuẩn ấy (Những ngưỡng này nằm trong miền giá trị của bảng). Từ đó, bài toán trở về việc đi tìm những véctơ tham biến thỏa mãn ngưỡng giá trị của các tiêu chuẩn trên.

Có nhiều cách thức để lập bảng tương tác và tìm véctơ tham biến hợp lệ. Trong công trình gần đây của nhóm tác giả [6], kỹ thuật tối ưu một hàm tiêu chuẩn đã được sử dụng để tìm kiếm. Kỹ thuật này tỏ ra khá hiệu quả khi đưa ra được một số lời giải tốt, thỏa mãn yêu cầu của các chuyên gia. Trong một số trường hợp còn thu được giá trị vượt trội ở nhiều tiêu chuẩn. Tuy nhiên cách này lại chưa mô tả được mối quan hệ giữa các tiêu chuẩn - tham biến và các tiêu chuẩn so với nhau nhằm giúp các chuyên gia có những thông tin cần thiết để sử dụng cho quá trình quyết toán ở những bối cảnh thiết kế cấp phối bê tông khác sau này. Thực tế sản xuất chỉ ra rằng, việc tìm ra các lời giải hợp lệ cũng như lời giải Pareto ngày nay là chưa đủ. Vì vậy, trong khuôn khổ bài báo, các tác giả sử dụng phương pháp khảo sát và tương tác trực quan (VIAM) dựa trên ứng dụng khỏa lấp không gian tham biến, được bước đầu giới thiệu trong các công 
trình của Gavriushin và Dang [2], Statnikov và cộng sự [8]. Sơ đồ ý tưởng của phương pháp này thể hiện trong Hình 2.

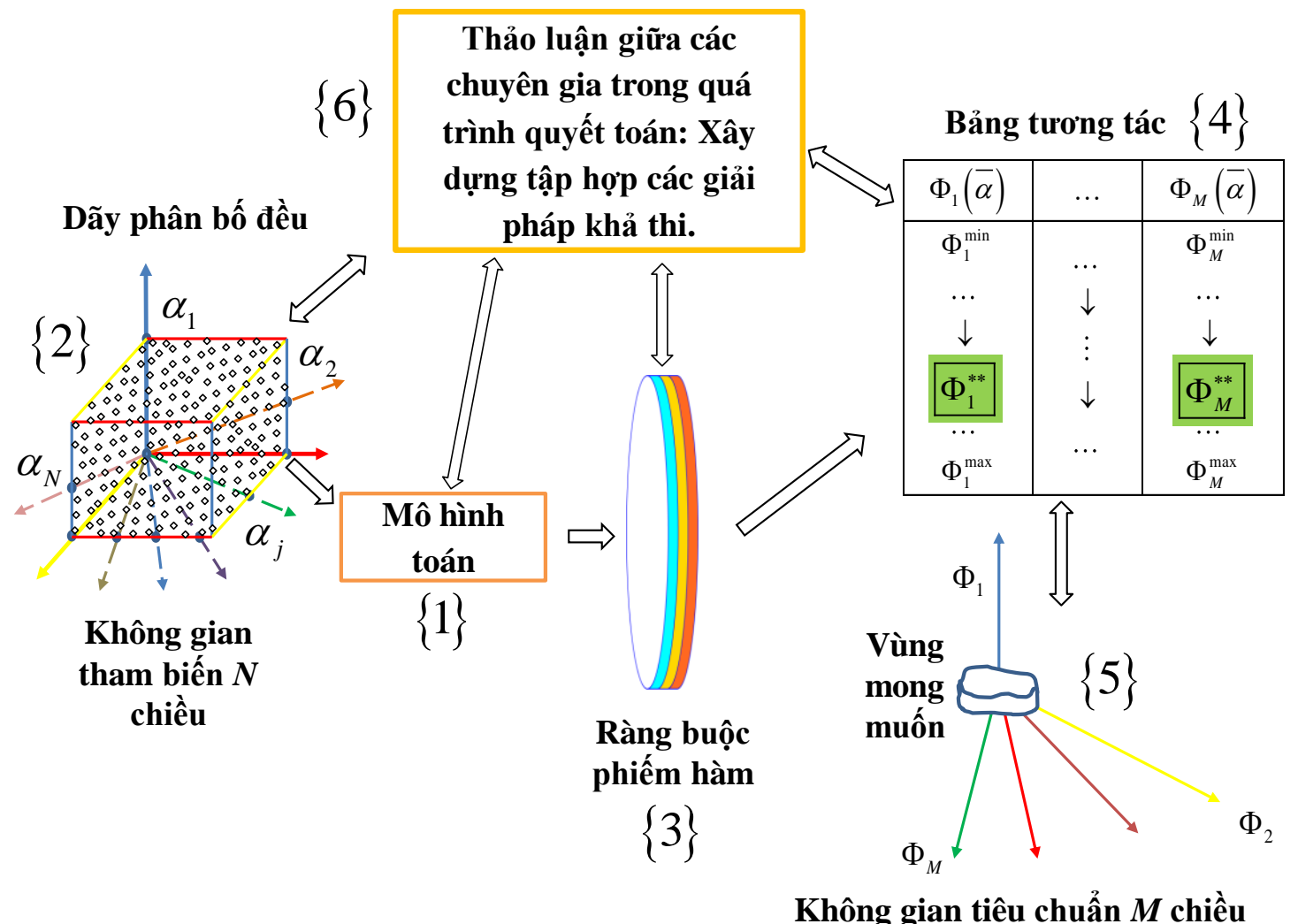

Hình 2: Phương pháp khảo sát không gian tham biến trong khuôn khổ VIAM

Bước đầu tiên cần xây dựng Mô hình toán (\{1\} hình 2) thiết kế cấp phối bê tông, bao gồm các đối tượng là không gian tham biến, tiêu chuẩn cùng các ràng buộc để đảm bảo yêu cầu kỹ thuật của bê tông cường độ - chất lượng cao. Mô hình này cho phép từ một véctơ tham biến bất kỳ tính được giá trị của các phiếm hàm và tiêu chuẩn để phục vụ cho quá trình cân nhắc và quyết toán của các chuyên gia thiết kế. Ta khỏa lấp Không gian tham biến $N$ chiều bằng một số lượng lớn điểm véctơ thử sử dụng các dãy phân bố đều, như LPtau $[2,3]$, và các dãy mặc định có sẵn trong các hệ điều hành như Windows $(\{2\}$ trong hình 2). Mô hình toán bước đầu tính ra giá trị các phiếm hàm để kiểm tra từng điều kiện ràng buộc ( $\{3\}$ trong hình 2). Chúng được coi như một "bộ lọc" để loại ra những giá trị không hợp lệ, chỉ còn để lại những véctơ thỏa mãn và đi vào Bảng tương tác ( $\{4\}$ trong hình 2$)$. Bảng tương tác là một bảng chứa $M$ cột, tương ứng với $M$ tiêu chuẩn chất lượng. Với những véctơ hợp lệ lọt qua bộ lọc phiếm hàm, chúng ta sẽ tính giá trị của các tiêu chuẩn và sắp xếp chúng theo thứ tự giảm dần từ trên xuống (Trên cùng là những giá trị tốt nhất, ví dụ như giá trị cực tiểu $\Phi_{i}^{\min }$ của tiêu chuẩn $i$, ở dưới là những giá trị xấu nhất, ví dụ như giá trị cực đại $\Phi_{i}^{\max }$ của tiêu chuẩn $i$ ). Các chuyên gia dựa vào bảng tương tác trên để chọn ra một giá trị ngưỡng $\Phi_{i}^{* *}$ cho từng tiêu chuẩn (Chúng được bôi màu xanh lá cây trong hình 2). Thỏa mãn được những giá trị ngưỡng này, các lời giải được rơi vào vùng "mong muốn" của các chuyên gia $(\{5\}$ trong hình 2). Tuy nhiên, vấn đề đặt ra là ở chỗ: trong nhiều tính huống chúng ta sẽ không thu được một lời giải hợp lệ nào, hoặc thu được rất ít. Việc khỏa lấp không gian tham biến mục đích là để khảo sát được môi trường toàn cục của nó. Nhưng với một số lượng điểm thử hữu hạn, nhiều khi ta không thể bắt gặp hoặc rơi được vào "vùng mong muốn". Khi đó, trong khuôn khổ VIAM, tác giả đề xuất kỹ thuật khỏa lấp không gian với một số các phương cách nhằm tháo gỡ các tình huống không có lời giải. Có 4 cách chính như sau: 
- Tăng số lượng điểm khỏa lấp trong không gian

- Thay đổi các dãy phân bố đều

- Thay đổi chính mô hình toán, như điều kiện biên của các tham biến, các ràng buộc và của tiêu chuấn

- Từng bước đi sâu và chính xác hóa miền lời giải hợp lệ bằng cách giải lại bài toán nhiều lần khi điều chỉnh mô hình toán

Cả bốn phương cách trên đều cần sự tư vấn của các chuyên gia thiết kế (Hội thoại $\{6\}$ trong hình 2 giữa các khâu tính toán và phân tích). Cùng xem xét lời giải chi tiết cho bài toán thiết kế cấp phối bê tông cường độ cao mà mô hình toán của nó được đề cập ở mục 2.

Bước 1: Tìm miền hợp lẹ ban đầu thỏa mãn các ràng buộc phiếm hàm

Khỏa lấp không gian 7 tham biến với $2^{16}=65536$ véctơ điểm thử bằng dãy phân bố đều LPtau. Trên cơ sở đó ta tính gia trị 10 phiếm hàm $f_{i}(i=1 . .10)$ nhưng không có một véctơ nào lọt qua được bộ lọc của 10 điều kiện ràng buộc này để đi vào bảng tương tác với các tiêu chuẩn. Để chắc chắn hơn, 90000 véc tở điểm thử với dãy phân bố đều Windows đã được tính toán tiếp để kiểm tra lại 10 ràng buộc. Tuy nhiên vẫn không thu được một lời giải hợp lệ nào. Đến đây, các chuyên gia quyết định kiểm tra xem những ràng buộc nào không được thỏa mãn dẫn tới sự loại trừ véctơ điểm thử ban đầu cho cả 2 lần tính toán (65 $536+90000=155536$ ). Số lượng véctơ điểm thử vi phạm từng ràng buộc và giá trị gần nhất với điều kiện ràng buộc có thể đạt cho từng phiếm hàm được thống kê trong Bảng 4.

Bảng 4: Thống kê sự vi phạm điều kiện ràng buộc của các véc tơ điểm thử

\begin{tabular}{cccc}
\hline Ràng buộc & $\begin{array}{c}\text { Số véc tơ điểm thử không } \\
\text { thỏa mãn } \\
{[\text { LPtau] }+[\text { Dãy Windows] }}\end{array}$ & $\begin{array}{c}\text { Giá trị gần nhất với điều kiện } \\
\text { răng buộc có thể đạt } \\
{[\text { LPtau] } /[\text { Dãy Windows] }}\end{array}$ & Phần trăm vi phạm \\
\hline$f_{1} \leq 0$ & $3711+5020=8731$ & $2.66 E-06 / 4.79 E-07$ & $5.61 \%$ \\
$f_{2} \leq 0$ & $906+1313=2219$ & $5.40 \mathrm{E}-05 / 3.12 E-05$ & $1.43 \%$ \\
$f_{3} \leq 0$ & $14569+19931=34500$ & $\mathbf{3 . 9 4 E - 0 7 / 1 . 3 7 E - 0 6}$ & $22.18 \%$ \\
$f_{4} \leq 0$ & $28437+39303=67740$ & $\mathbf{1 . 1 5 E - 0 6 / 6 . 5 6 E - 0 6}$ & $43.55 \%$ \\
$f_{5} \leq 0$ & $57+82=139$ & $\mathbf{3 . 1 4 E - 0 1 / 5 . 2 2 E - 0 1}$ & $0.09 \%$ \\
$f_{6} \leq 0$ & $11237+15363=26600$ & $\mathbf{9 . 1 6 E - 0 4 / 1 . 6 4 E - 0 2}$ & $17.1 \%$ \\
$f_{7} \leq 0$ & $2085+2882=4967$ & $1.11 \mathrm{E}-06 / \mathbf{1 . 4 9 E}-07$ & $3.19 \%$ \\
$f_{8} \leq 0$ & $649+894=1543$ & $\mathbf{3 . 7 8 E - 0 7 / 4 . 9 7 E - 0 7}$ & $1 \%$ \\
$f_{9}=0$ & $3885+5212=9097$ & $\mathbf{2 . 0 8 E - 0 2 / 4 . 8 7 E - 0 2}$ & $5.85 \%$ \\
$f_{10} \leq 0$ & 0 & $0 / 0$ & $0 \%$ \\
\hline
\end{tabular}

Nhìn vào bảng thống kê, ta thấy 9 ràng buộc đầu tiên đều không được thỏa mãn, dẫn tới không thể tìm được một lời giải hợp lệ để đi vào bảng tương tác. Dĩ nhiên, chúng ta có thể tăng điểm thử lên nhiều hơn nữa, nhưng điều đó không đưa ra một phương pháp xác định số lượng cần thiết trong trường hợp tổng quát, có nghĩa là thời gian tìm kiếm là không thể kiểm soát được. Trong bài báo này, phương pháp xử lý tình huống nằm ở chỗ cần thay đổi mô hình toán, cụ thể là giá trị ngưỡng của các điều kiện ràng buộc phiếm hàm. Theo bảng 4 , các ràng buộc 3,4 bị vi phạm nhiều nhất, nhưng giá trị thu được cũng khá gần với 0 , vì vậy, các chuyên gia quyêt định sửa lại 2 điều kiện này là $f_{3} \leq 10^{-4}$, là $f_{4} \leq 10^{-4}$. Các phiếm hàm 1 , $2,5,7,8$ bị vi phạm không quá nhiều và giá trị khá gần 0 , nên bước đầu có thể sửa lại là $f_{1} \leq 10^{-5}, f_{2} \leq 10^{-}$ $5, f_{5} \leq 10^{-5}, f_{7} \leq 10^{-5}, f_{8} \leq 10^{-5}$. Mặt khác, tiêu chuẩn $f_{9}$ có vai trò đảm bảo tổng thể tích của hốn hợp bê tông bằng với dung tích thiết kế thường là một tiêu chuẩn rất khó thực hiện chính xác $100 \%$, giá trị gần nhất mà 155536 phép thử đã tiến hành là 0.021 cũng nói lên điều đó. Do vậy các chuyên gia cho phép chỉnh lại $f_{9}= \pm 1$ tức là tổng thể tích hốn hợp bê tông bước đầu sẽ cho phép sai số là 1 lít.

Giải lại với mô hình bài toán mới, khỏa lấp không gian tham biến ban đầu với $3 \times 2^{15}$ điểm thử bằng dãy LPtau, ta thu được 25 lời giải hợp lệ, chúng "lọt qua" rào cản ràng buộc để đi vào bảng tương tác. Tuy nhiên, ta chưa thể sử dụng được chúng vì ràng buộc 9 đã được nới lỏng rất nhiều. 25 lời giải này chỉ có ý nghĩa giúp chúng ta tiển gần về "miền hợp lệ" mà thôi. Để xác định được miền này, chúng ta sử dụng công cụ trực quan là biểu đồ phân bố lời giải trong các hình $3 \div 8$ : 


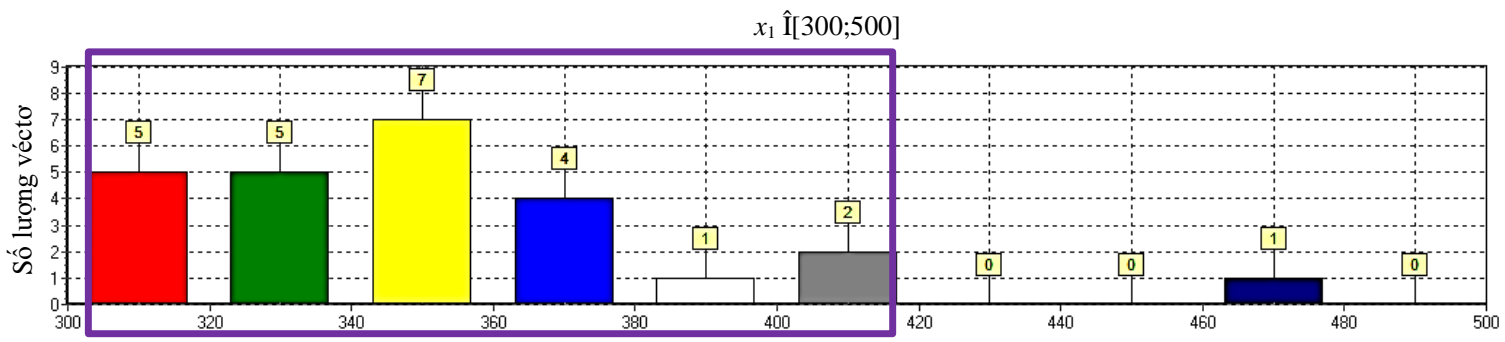

Hình 3: Biểu đồ phân bố lời giải hợp lệ của tham biến $x_{1}$

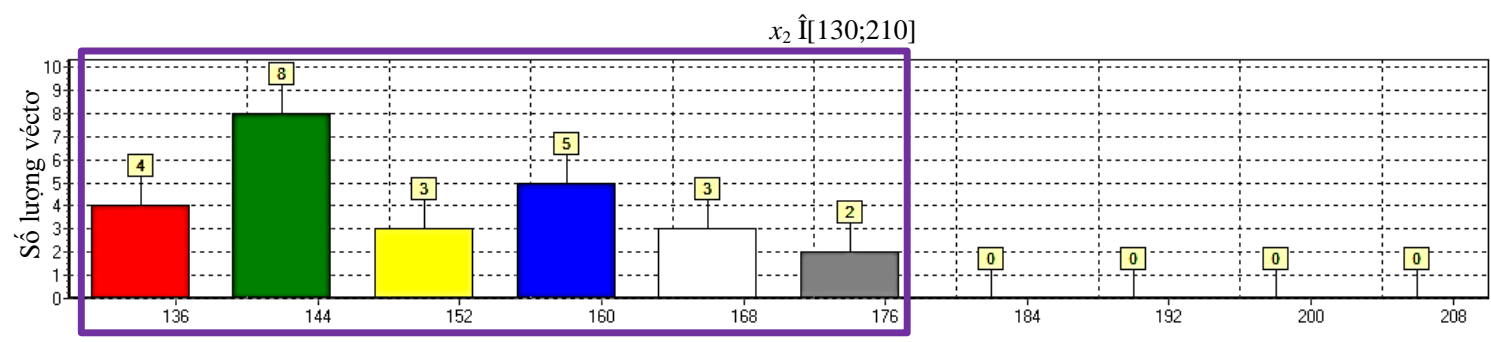

Hình 4: Biểu đồ phân bố lời giải hợp lệ của tham biến $x_{2}$

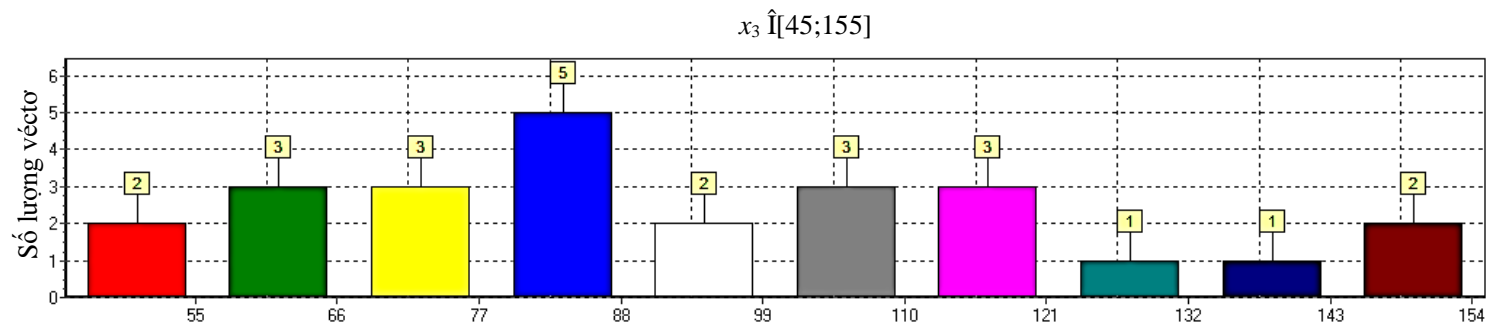

Hình 5: Biểu đồ phân bố lời giải hợp lệ của tham biến $x_{3}$

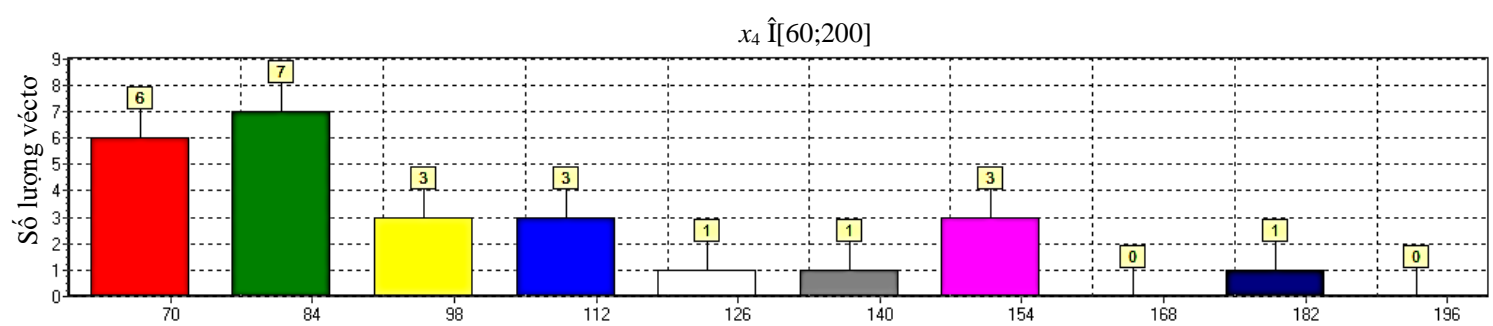

Hình 6: Biểu đồ phân bố lời giải hợp lệ của tham biến $x_{4}$

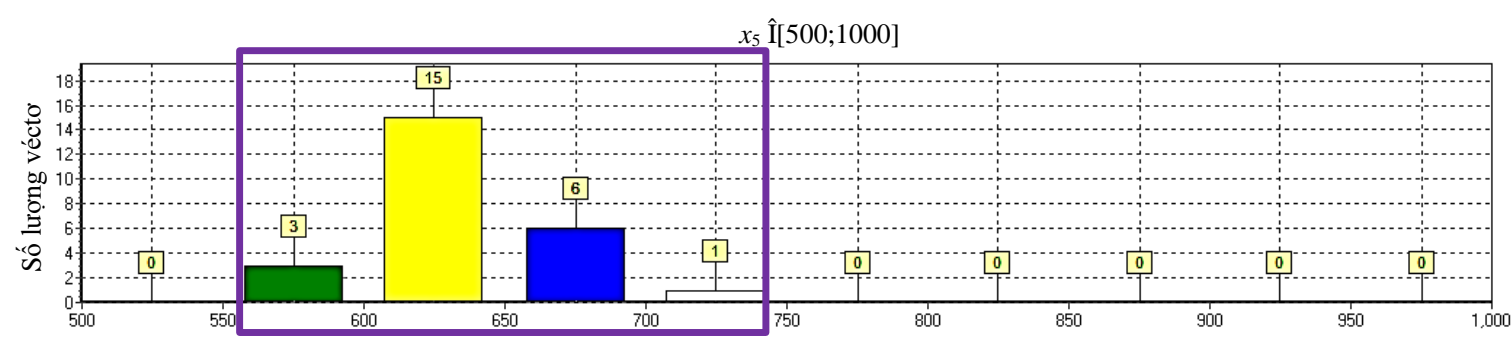

Hình 7: Biểu đồ phân bố lời giải hợp lệ của tham biến $x_{5}$ 


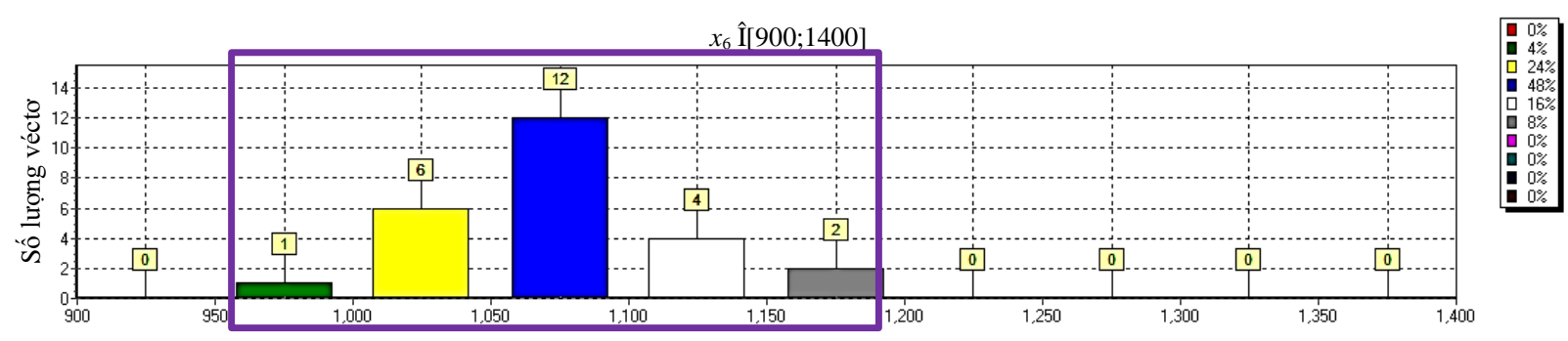

Hình 8: Biểu đồ phân bố lời giải hợp lệ của tham biến $x_{6}$

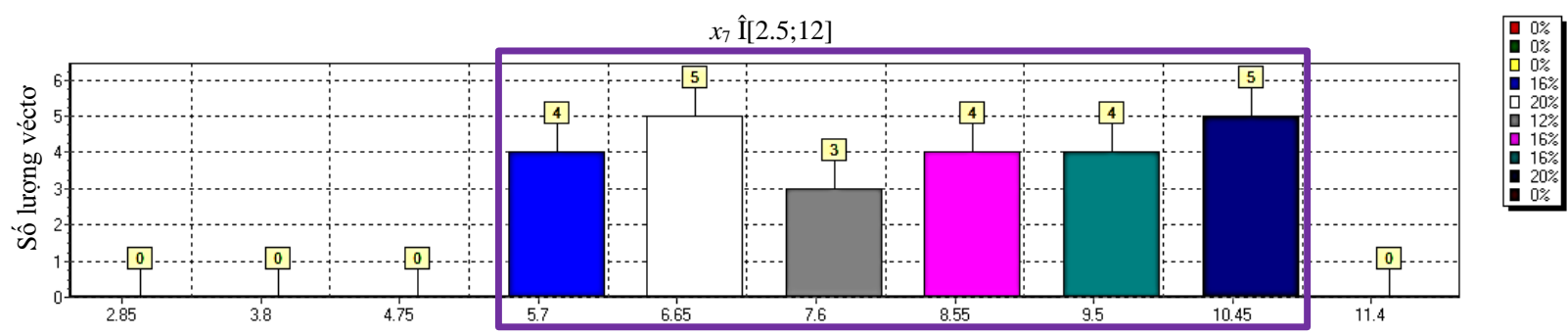

Hình 9: Biểu đồ phân bố lời giải hợp lệ của tham biến $x_{7}$

Trong các biểu đồ này, miền xác định của các tham biến được chia ra 10 khoảng, trong mỗi khoảng là các hình chữ nhật với các cao độ của chúng, cùng phía trên có gắn các con số thể hiện số lượng lời giải hợp lệ mà giá trị của tham biến đó rơi vào (nếu có). Hình chữ nhật rỗng màu tím bao xung quanh các hình chữ nhật thể hiện vùng lời giải hợp lệ của các tham biến. Đáng lưu ý là ở tham biến số 1 . Mặc dù theo biểu đồ, miền lời giải hợp lệ phân bố từ [300; 480] như hình 3 , nhưng ở giữa khoảng [420; 460] lại không có một lời giải nào cả. Thêm vào đó các lời giải hợp lệ đa số tập trung vào vùng $[300,420]$, nên việc bỏ đi 1 lời giải ở miền $[460 ; 480]$ có thể chấp nhận được. Lý do, nếu ta kéo dài đến 480 thì không gian sẽ rộng hơn, việc tìm kiếm những lời giải các bước sau sẽ khó khăn và không hiệu quả vì ta đã biết rằng từ 420 trở về sau thì sẽ có rất ít các lời giải hiện hữu tại đó. Vậy, dựa vào 7 biểu đồ trên, ta thu được miền xác định mới cho các tham biến như trong Bảng 5 :

Bảng 5: Miền xác định mới của các tham biến - lần thay đổi thứ 1

\begin{tabular}{|ccccccc|}
\hline$x_{1} \hat{\mathrm{I}}$ & $x_{2} \hat{\mathrm{I}}$ & $x_{3} \hat{\mathrm{I}}$ & $x_{4} \hat{\mathrm{I}}$ & $x_{5} \hat{\mathrm{I}}$ & $x_{6} \hat{\mathrm{I}}$ & $x_{7} \hat{\mathrm{I}}$ \\
\hline$[300 ; 420]$ & {$[130 ; 180]$} & {$[45 ; 155]$} & {$[60 ; 200]$} & {$[550 ; 750]$} & {$[950 ; 1200]$} & {$[4.75 ; 11.4]$} \\
\hline
\end{tabular}

Với miền xác định mới, ta tiếp tục theo lộ trình khỏa lấp không gian với $3 \times 2^{14}$ véctơ điểm thử bằng dãy phân bố đều LPtau. Lần này ta thu được 192 lời giải hợp lệ. Trong các biểu đồ phân bố, các lời giải này đều có mặt trong tất cả 10 khoảng chia nên không có gì để điều chỉnh miền xác định của chúng nữa. Tuy nhiên, lúc này là thời điểm cần siết chặt lại ràng buộc 9 . Các chuyên gia khuyến nghị điều kiện có thể chấp nhận được là $f_{9}= \pm 0.02$ (nghĩa là có thể chấp nhận $2 \%$ sai số dung tích hỗn hợp bê tông trong thực tế sản xuất).

Sử dụng lại dãy phân bố đều Windows với 80000 điểm thử, ta chỉ thu được 4 lời giải hợp lệ với các biểu đồ phân bố của chúng (công cụ giống như ở hình $3 \div 9$ ). Dựa vào đó ta lại điều chỉnh miền xác định của tham biến, lần thứ 2 :

Bảng 6: Miền xác định mới của các tham biến - lần thay đổi thứ 2

\begin{tabular}{|ccccccc|}
\hline$x_{1} \hat{\mathrm{I}}$ & $x_{2} \hat{\mathrm{I}}$ & $x_{3} \hat{\mathrm{I}}$ & $x_{4} \hat{\mathrm{I}}$ & $x_{5} \hat{\mathrm{I}}$ & $x_{6} \hat{\mathrm{I}}$ & $x_{7} \hat{\mathrm{I}}$ \\
\hline$[300 ; 360]$ & {$[130 ; 165]$} & {$[45 ; 110]$} & {$[70 ; 170]$} & {$[620 ; 700]$} & {$[975 ; 1200]$} & {$[4.75 ; 9.975]$} \\
\hline
\end{tabular}


Lúc này, ta sử dụng dãy LPtau để khỏa lấp không gian tham biến trong bảng 6 với $3 \times 2^{15}$ điểm thử. Ta thu được 40 lời giải hợp lệ thỏa mãn 10 ràng buộc phiếm hàm. Tính giá trị các tiêu chuẩn và lập bảng tương tác như sau (bảng 7 và 8 ):

Buớc 2: Lâp bảng tuơng tác và thiết lập các nguõng giá trị cho các tiêu chuẩn

Bảng 7: Bảng tương tác rút gọn với 40 véctơ hợp lệ cùng giá trị các tiêu chuẩn $\boldsymbol{\Phi}_{1} \div \boldsymbol{\Phi}_{3}$

\begin{tabular}{|c|c|c|c|c|c|}
\hline \multicolumn{2}{|c|}{ Tiêu chuẩn $\boldsymbol{\Phi}_{1}$} & \multicolumn{2}{|c|}{ Tiêu chuẩn $\boldsymbol{\Phi}_{2}$} & \multicolumn{2}{|c|}{ Tiêu chuẩn $\boldsymbol{\Phi}_{3}$} \\
\hline $\begin{array}{c}\text { Số hiệu véctơ } \\
\#\end{array}$ & Giá trị $\boldsymbol{\Phi}_{1}$ & Số hiệu véctơ & Giá trị $\boldsymbol{\Phi}_{2}$ & $\begin{array}{c}\text { Số hiệu véctơ } \\
\#\end{array}$ & Giá trị $\boldsymbol{\Phi}_{3}$ \\
\hline$\# 64666$ & $1.49825 \mathrm{E}-14$ & $\# 38772$ & 1262428.5 & $\# 90240$ & 300.2403259 \\
\hline \#97433 & 4.17022E-14 & \#25193 & 1278677.625 & \#95760 & 301.9761658 \\
\hline \#95759 & 4.23573E-14 & \#42617 & 1315916.25 & \#10512 & 302.010498 \\
\hline \#50022 & $4.57118 \mathrm{E}-14$ & \#95760 & 1339561.5 & \#30648 & 307.0147705 \\
\hline$\bullet \bullet \bullet$ & $\bullet \bullet \bullet$ & $\bullet \bullet$ & •.• & ••• & ••• \\
\hline \#95467 & $1.70306 \mathrm{E}-13$ & \#30223 & 1366253.25 & \#38772 & 310.9945679 \\
\hline \#21589 & $1.77858 \mathrm{E}-13$ & \#33084 & 1376642.75 & \#77772 & 312.1769714 \\
\hline \#17891 & $2.0504 \mathrm{E}-13$ & \#21589 & 1426249.875 & \#24604 & 313.1304932 \\
\hline \#51774 & $2.12792 \mathrm{E}-13$ & \#94858 & 1435086.5 & \#71836 & 313.3818054 \\
\hline \#63593 & $2.14162 \mathrm{E}-13$ & \#86665 & 1446434.125 & \#33084 & 314.180603 \\
\hline ••• & •.• & $\bullet \bullet$ & $\bullet \bullet$ & •.• & $\bullet$ \\
\hline \#38772 & $3.8726 \mathrm{E}-13$ & \#71622 & 1726736.25 & \#97627 & 351.268158 \\
\hline \#25193 & $4.25888 \mathrm{E}-13$ & \#95759 & 1766834 & \#30223 & 356.350708 \\
\hline \#42617 & $4.58956 \mathrm{E}-13$ & \#67875 & 1793932.25 & \#95759 & 356.3511658 \\
\hline
\end{tabular}

Bảng 8: Bảng tương tác rút gọn với 40 véctơ hợp lệ cùng giá trị các tiêu chuẩn $\boldsymbol{\Phi}_{4} \div \boldsymbol{\Phi}_{6}$

\begin{tabular}{|c|c|c|c|c|c|}
\hline \multicolumn{2}{|c|}{ Tiêu chuẩn $\boldsymbol{\Phi}_{4}$} & \multicolumn{2}{|c|}{ Tiêu chuẩn $\boldsymbol{\Phi}_{5}$} & \multicolumn{2}{|c|}{ Tiêu chuẩn $\boldsymbol{\Phi}_{6}$} \\
\hline $\begin{array}{c}\text { Số hiệu véctơ } \\
\#\end{array}$ & Giá trị $\boldsymbol{\Phi}_{4}$ & $\begin{array}{c}\text { Số hiệu véctơ } \\
\#\end{array}$ & Giá trị $\boldsymbol{\Phi}_{5}$ & $\begin{array}{c}\text { Số hiệu véctơ } \\
\#\end{array}$ & Giá trị $\boldsymbol{\Phi}_{6}$ \\
\hline \#42617 & 47.264328 & \#30223 & 70.65002441 & \#42617 & 5.159239769 \\
\hline \#95759 & 47.56534576 & \#25193 & 75.17883301 & \#77772 & 5.168766975 \\
\hline \#87753 & 54.05979156 & \#38772 & 76.70928955 & \#24949 & 5.358318329 \\
\hline \#27462 & 54.5552063 & \#17891 _ _ & 81.88659668 & \#10512 _ & 5.367088318 \\
\hline •.• & •.• & ••• & ••• & $\bullet \bullet$ & $\bullet$ \\
\hline \#24949 & 57.77664185 & \#24949 & 133.8702393 & \#33084 & 7.416156292 \\
\hline \#46670 & 58.20610046 & \#97433 & 136.3475037 & \#95760 & 7.830538273 \\
\hline \#77733 & 58.8740921 & \#10512 & 139.6228027 & \#52220 & 7.955909252 \\
\hline \#10512 & 61.12701416 & \#63593 & 141.3851929 & \#11755 & 8.176035881 \\
\hline \#94858 & 62.26016998 & \#27462 & 141.6583252 & \#29771 & 8.254647255 \\
\hline$\bullet$ & •.• & ••• & ••• & ••• & •.• \\
\hline \#95760 & 106.4715958 & \#95759 & 158.344574 & \#95467 & 9.825631142 \\
\hline \#52220 & 107.6920319 & \#67875 & 161.2895203 & \#67875 & 9.845562935 \\
\hline \#66234 & 109.9370193 & \#71622 & 166.3554382 & \#30223 & 9.91297245 \\
\hline
\end{tabular}

Trong các bảng tương tác này, các tiêu chuẩn sau của mỗi một véc tơ điểm thử tham biến được tính giá trị và sắp xếp theo thứ tự tăng dần từ trên xuống dưới. Các chuyên gia dựa vào bảng này biết được miền giá trị của các tiêu chuẩn để từ đó thiết lập nên các "ngưỡng" cho phép. Trong bảng những ngưỡng này là những véc tơ và giá trị tiêu chuẩn tương ứng được bao viền xung quanh bằng những khung hình chữ nhật có màu. Giả sử các chuyên gia xác định rằng: Hệ số thẩm thấu ion clorua ở ngày thứ $28\left(\boldsymbol{\Phi}_{1}\right)$ cần cực tiểu hóa và trong trường hợp xấu nhất không được lớn hơn giá trị 2.0504E-13 (tương ứng với véc tơ điểm thử \#17891); Giá thành của $1 \mathrm{~m}^{3}$ bê tông $\left(\boldsymbol{\Phi}_{2}\right)$ không được đắt hơn $1426249.875 \mathrm{VND}$ (tương ứng 
với véc tơ điểm thử \#21589); Hai giá trị vừa lựa chọn đều ở giữa khoảng của miền giá trị 2 tiêu chuẩn 1 và 2 . Tiếp theo, 2 tiêu chuẩn $\boldsymbol{\Phi}_{3}$ (Hàm lượng xi măng Portland trong $1 \mathrm{~m}^{3}$ bê tông) và $\boldsymbol{\Phi}_{4}$ (Hàm lượng tro bay trong $1 \mathrm{~m}^{3}$ bê tông) các chuyên gia nhận định rằng toàn bộ các giá trị trong bảng đều thỏa mãn mong muốn của họ nên ngưỡng của chúng có thể ở mức đáy thấp nhất. Còn lại 2 tiêu chuẩn hàm lượng xỉ lò cao trong $1 \mathrm{~m}^{3}$ bê tong $\left(\boldsymbol{\Phi}_{5}\right)$ và hàm lượng phụ gia hóa học trong $1 \mathrm{~m}^{3}$ bê tông $\left(\boldsymbol{\Phi}_{6}\right)$ cũng cần cực tiểu hóa hết sức có thể và cũng không được vượt quá giá trị là 139.6228027 (\#10512) và 7.955909252 (\#52220) tương ứng. Sau khi đặt xong những ngưỡng tiêu chuẩn này, từ 40 véc tơ điểm thử chỉ còn lại duy nhất 2 véc tơ hợp lệ là \#21589 và \#17891, chúng chính là những véc tơ lời giải tối ưu Pareto cần tìm kiếm. Tuy nhiên để khảo sát kỹ hơn và tìm được nhiều lời giải hơn nhằm giúp các chuyên gia đánh giá về miền giá trị các tiêu chuẩn, chúng ta có thể tiếp tục khoanh vùng tham biến để tìm kiếm:

Bước 3: Tìm thêm lời giải tối ưu Pareto.

Sử dụng công cụ biểu đồ phân bố lời giải hợp lệ (công cụ giống như ở hình $3 \div 9$ ), ta thu được miền xác định mới của tham biến xung quanh 2 lời giải \#21589 và \#17891 trong Bảng 9.

Bảng 9: Miền xác định mới của các tham biến - lần thay đổi thứ 3

\begin{tabular}{|ccccccc|}
\hline$x_{1} \hat{\mathrm{I}}$ & $x_{2} \hat{\mathrm{I}}$ & $x_{3} \hat{\mathrm{I}}$ & $x_{4} \hat{\mathrm{I}}$ & $x_{5} \hat{\mathrm{I}}$ & $x_{6} \hat{\mathrm{I}}$ & $x_{7} \hat{\mathrm{I}}$ \\
\hline$[336 ; 348]$ & {$[140 ; 151]$} & {$[71.5 ; 91]$} & {$[80 ; 110]$} & {$[656 ; 696]$} & {$[1035 ; 1147.5]$} & {$[4.75 ; 7.315]$} \\
\hline
\end{tabular}

Khỏa lấp không gian với 90000 điểm thử bằng dãy phân bố đều Windows. Tuy nhiên ở đây ta lại thắt chặt điều kiện của các tiêu chuẩn hơn 1 chút nữa so với ở trên như sau: $\boldsymbol{\Phi}_{1} \rightarrow \mathrm{MIN} \leq 2 \mathrm{E}-13 ; \boldsymbol{\Phi}_{2} \rightarrow \mathrm{MIN} \leq$ 1.4E6; $\boldsymbol{\Phi}_{3} \rightarrow \mathrm{MIN} \leq 400 ; \boldsymbol{\Phi}_{6} \rightarrow \mathrm{MIN} \leq 110 ; \boldsymbol{\Phi}_{5} \rightarrow \mathrm{MIN} \leq 140 ; \boldsymbol{\Phi}_{6} \rightarrow \mathrm{MIN} \leq 8$. Ta thu được 10 lời giải tối ưu Pareto, kết hợp với \#21589 và \#17891 ở bước 2, ta thu được 12 lời giải. Giá trị các tiêu chuẩn của chúng thể hiện trong Bảng 10 và giá trị các tham biến thể hiện trong Bảng 11.

Với 12 lời giải Pareto này, các chuyên gia có thể lựa chọn 1 trong số chúng để thiết kế cấp phối bê tông cường độ cao - chất lượng cao theo mục tiêu được đặt ra ban đầu.

Bảng 10: Giá trị các tiêu chuẩn của 12 lời giải Pareto

\begin{tabular}{ccccccc}
\hline $\begin{array}{c}\text { Số hiệu } \\
\text { vécto }\end{array}$ & $\boldsymbol{\Phi}_{1} \rightarrow \mathrm{MIN}$ & $\boldsymbol{\Phi}_{2} \rightarrow \mathrm{MIN}$ & $\boldsymbol{\Phi}_{3} \rightarrow \mathrm{MIN}$ & $\boldsymbol{\Phi}_{4} \rightarrow \mathrm{MIN}$ & $\boldsymbol{\Phi}_{5} \rightarrow \mathrm{MIN}$ & $\boldsymbol{\Phi}_{6} \rightarrow \mathrm{MIN}$ \\
\hline Min: & $1.56 \mathrm{E}-13$ & $1.35 \mathrm{E}+06$ & $3.37 \mathrm{E}+02$ & $7.35 \mathrm{E}+01$ & $8.19 \mathrm{E}+01$ & $5.24 \mathrm{E}+00$ \\
Max: & $2.05 \mathrm{E}-13$ & $1.43 \mathrm{E}+06$ & $3.48 \mathrm{E}+02$ & $9.04 \mathrm{E}+01$ & $1.06 \mathrm{E}+02$ & $7.11 \mathrm{E}+00$ \\
\#17891 & $2.05 \mathrm{E}-13$ & $1.36 \mathrm{E}+06$ & $3.47 \mathrm{E}+02$ & $8.23 \mathrm{E}+01$ & $8.19 \mathrm{E}+01$ & $7.11 \mathrm{E}+00$ \\
(Bước 2) & & & & & & \\
\#21589 & $1.78 \mathrm{E}-13$ & $1.43 \mathrm{E}+06$ & $3.40 \mathrm{E}+02$ & $7.96 \mathrm{E}+01$ & $1.06 \mathrm{E}+02$ & $5.45 \mathrm{E}+00$ \\
(Bước 2) & & & & & & \\
$\# 3351$ & $1.56 \mathrm{E}-13$ & $1.39 \mathrm{E}+06$ & $3.40 \mathrm{E}+02$ & $9.04 \mathrm{E}+01$ & $9.60 \mathrm{E}+01$ & $5.54 \mathrm{E}+00$ \\
$\# 21629$ & $1.95 \mathrm{E}-13$ & $1.39 \mathrm{E}+06$ & $3.45 \mathrm{E}+02$ & $7.50 \mathrm{E}+01$ & $9.71 \mathrm{E}+01$ & $5.30 \mathrm{E}+00$ \\
$\# 26522$ & $1.87 \mathrm{E}-13$ & $1.39 \mathrm{E}+06$ & $3.42 \mathrm{E}+02$ & $7.89 \mathrm{E}+01$ & $9.51 \mathrm{E}+01$ & $5.83 \mathrm{E}+00$ \\
$\# 28684$ & $1.94 \mathrm{E}-13$ & $1.38 \mathrm{E}+06$ & $3.45 \mathrm{E}+02$ & $8.20 \mathrm{E}+01$ & $9.01 \mathrm{E}+01$ & $6.61 \mathrm{E}+00$ \\
$\# 56021$ & $1.94 \mathrm{E}-13$ & $1.35 \mathrm{E}+06$ & $3.37 \mathrm{E}+02$ & $8.45 \mathrm{E}+01$ & $8.64 \mathrm{E}+01$ & $6.30 \mathrm{E}+00$ \\
$\# 56394$ & $1.99 \mathrm{E}-13$ & $1.39 \mathrm{E}+06$ & $3.42 \mathrm{E}+02$ & $7.69 \mathrm{E}+01$ & $9.42 \mathrm{E}+01$ & $6.29 \mathrm{E}+00$ \\
$\# 60029$ & $1.87 \mathrm{E}-13$ & $1.39 \mathrm{E}+06$ & $3.46 \mathrm{E}+02$ & $8.12 \mathrm{E}+01$ & $9.18 \mathrm{E}+01$ & $6.57 \mathrm{E}+00$ \\
$\# 63389$ & $1.61 \mathrm{E}-13$ & $1.39 \mathrm{E}+06$ & $3.40 \mathrm{E}+02$ & $8.91 \mathrm{E}+01$ & $9.28 \mathrm{E}+01$ & $6.23 \mathrm{E}+00$ \\
$\# 67933$ & $1.77 \mathrm{E}-13$ & $1.38 \mathrm{E}+06$ & $3.38 \mathrm{E}+02$ & $7.81 \mathrm{E}+01$ & $9.68 \mathrm{E}+01$ & $5.51 \mathrm{E}+00$ \\
$\# 75706$ & $1.97 \mathrm{E}-13$ & $1.37 \mathrm{E}+06$ & $3.48 \mathrm{E}+02$ & $7.35 \mathrm{E}+01$ & $9.24 \mathrm{E}+01$ & $5.24 \mathrm{E}+00$ \\
\hline
\end{tabular}


Bảng 11: Giá trị các tham biến của 12 lời giải Pareto

\begin{tabular}{cccccccc}
\hline $\begin{array}{c}\text { Số hiệu } \\
\text { véctó }\end{array}$ & $x_{1}$ & $x_{2}$ & $x_{3}$ & $x_{4}$ & $x_{5}$ & $x_{6}$ & $x_{7}$ \\
\hline Min: & $3.37 \mathrm{E}+02$ & $1.40 \mathrm{E}+02$ & $7.35 \mathrm{E}+01$ & $8.19 \mathrm{E}+01$ & $6.57 \mathrm{E}+02$ & $1.05 \mathrm{E}+03$ & $5.24 \mathrm{E}+00$ \\
Max: & $3.48 \mathrm{E}+02$ & $1.48 \mathrm{E}+02$ & $9.04 \mathrm{E}+01$ & $1.06 \mathrm{E}+02$ & $6.95 \mathrm{E}+02$ & $1.12 \mathrm{E}+03$ & $7.11 \mathrm{E}+00$ \\
\#17891 & 346.789 & 141.421 & 82.330 & 81.887 & 661.106 & 1113.050 & 7.110 \\
(Bước 2) & & & & & & & \\
\#21589 & 339.882 & 147.569 & 79.640 & 105.507 & 688.284 & 1054.850 & 5.449 \\
(Bước 2) & & & & & & \\
\#3351 & 339.760 & 142.796 & 90.403 & 95.971 & 663.614 & 1090.502 & 5.542 \\
\#21629 & 344.963 & 144.970 & 75.018 & 97.055 & 660.785 & 1102.372 & 5.299 \\
\#26522 & 342.030 & 143.397 & 78.920 & 95.057 & 695.309 & 1068.744 & 5.834 \\
\#28684 & 345.161 & 143.784 & 81.987 & 90.133 & 680.972 & 1079.532 & 6.611 \\
\#56021 & 337.245 & 140.463 & 84.516 & 86.358 & 656.924 & 1122.777 & 6.297 \\
\#56394 & 341.983 & 143.829 & 76.854 & 94.206 & 672.212 & 1094.371 & 6.290 \\
\#60029 & 346.380 & 143.756 & 81.237 & 91.787 & 686.636 & 1071.759 & 6.573 \\
\#63389 & 339.789 & 141.462 & 89.097 & 92.801 & 694.859 & 1064.713 & 6.233 \\
\#67933 & 338.134 & 141.188 & 78.059 & 96.784 & 668.436 & 1106.554 & 5.510 \\
\#75706 & 347.811 & 142.682 & 73.495 & 92.443 & 672.705 & 1100.846 & 5.244 \\
\hline
\end{tabular}

\section{KẾT LUẬN}

Đối với lời giải cho bài toán tối ưu đa mục tiêu, ứng dụng trong việc thiết kế cấp phối bê tông cường độ chất lượng cao, lời giải ở đây không phải là duy nhất. Bởi lẽ lời giải này là tập hợp giá trị của nhiều tiêu chuẩn, nhưng mỗi 1 tiêu chuẩn lại có tầm quan trọng khác nhau dưới góc nhìn của các chuyên gia khác nhau, trong một bối cảnh sản xuất cụ thể. Do vậy, việc đánh giá lời giải nào đó ưu việt hơn, dựa vào giá trị của 1 hàm tương đương cho tất cả các tiêu chuẩn, là điều không toàn diện.

Ý nghĩa của sự tương tác và giúp đỡ của các chuyên gia trong quá trình tìm kiếm miền hợp lệ là vô cùng quan trọng trong việc giải quyết các bài toán đa mục tiêu. Việc cố định mô hình toán và đặt hi vọng lên các giải thuật tối ưu nhiều khi không đem lại hiệu quả cao. Thực tế cho thấy, các ràng buộc, điều kiện, tiêu chuẩn trong mô hình toán có thể được nới lỏng, thắt chặt, thay đổi liên tục phục vụ cho quá trình tìm kiếm lời giải diễn ra thuận lợi nhất là một cách tiếp cận mang tính linh hoạt và đòi hỏi phải có sự tham gia của yếu tố "con người", khó có thể tự động hóa hoàn toàn.

Ta đã tìm được 12 lời giải cho các tình huống yêu cầu khác nhau về các tiêu chuẩn trong quá trình tìm kiếm phương án thiết kế cấp phối bê tông cường độ cao - chất lượng cao. Chúng đều là những lời giải Pareto, cho phép các chuyên gia lựa chọn trong tình huống được chỉ định. Bài toán còn có thể mở rộng hơn với những tham biến, ràng buộc, cũng như tiêu chuẩn khác nhau khi thay đổi số lượng và tính chất các thành phần hợp chất làm nên bê tông cường độ cao - chất lượng cao.

\section{TÀI LIỆU THAM KHẢO}

[1]. Aitcin, P.C. (2000). Cements of yesterday and today: Concrete of tomorrow. Cement and Concrete Research 30 (9), p. 1349-1359.

[2]. Gavriushin S.S. and Dang M. (2013). Multi-criteria design pressure vessel, manufactured from composite materials by the method of winding. Advanced Composite Materials and Technologies for Aerospace Applications, Wrexham, North Wales, UK, p. 60-66.

[3]. Gavriushin, S.S. and Dang, M. (2016) Multicriteria management of the metal cutting process. Journal of higher educational institutions: Machine building, ISSN 0536 - 1044, № 10, p. 82-95. 
[4]. Hassan, K.E., Cabrera, J.G., Maliehe, R.S. (2000) The effect of mineral admixtures on the properties of highperformance concrete. Cement and Concrete Composites 22 (4), p. 267-271.

[5]. Neville, A.M. and Aitcin, P.C. (1998). High-performance concrete - An overview. Materials and Structures 31 (3), p. $111-117$.

[6]. Nguyen V.D and Dang H.M (2016) High performance concrete mixture proportioning: Multi-objective optimization approach, Journal of Science of Ho Chi Minh City Open University 20(4), p. 65-76.

[7]. Kỷ yếu Hội nghị Bê tông châu Á lần thứ 7 với chủ đề "Phát triển bê tông bền vững cho hiện tại và tương lai", Hà nội 30/10-2/11/2016.

[8]. Statnikov R.B., Gavriushin S.S., Dang M., Statnikov A.R. (2014). Multicriteria design of composite pressure vessels. International Journal of Multicriteria Decision Making, Vol. 4, No. 3, p. 252-278.

[9]. Xie, X., Zheng, Y., Tian, F. (2011). Multi-objective Optimized Design of High-Performance concrete Based on Matlab. Advanced Materials Research, Vols 261-263, p 202-207.

Ngày nhận bài: 01/04/2017

Ngày chấp nhận đăng: 20/05/2017 